\title{
Identification and differentiation of Candida species using specific polymerase chain reaction (PCR) amplification of the phospholipase $B$ gene
}

\author{
Nabil .S. Harmal ${ }^{1,2}$, Alireza Khodavandi ${ }^{3}$, Mohammed .A. Alshawsh ${ }^{4}$, Farida Jamal ${ }^{2}$, Zamberi \\ Sekawi ${ }^{2}, \mathrm{Ng} \mathrm{Kee} \mathrm{Peng}{ }^{5}$ and Pei Pei Chong ${ }^{6 *}$ \\ ${ }^{1}$ Department of Medical Microbiology, Faculty of Medicine and Health Sciences, Sana'a University, Sana'a, Yemen. \\ ${ }^{2}$ Department of Medical Microbiology and Parasitology, Faculty of Medicine and Health Sciences, University Putra \\ Malaysia, 43400 Selangor, Malaysia. \\ ${ }^{3}$ Department of Basic Sciences, Gachsaran Branch, Islamic Azad University, Gachsaran, Iran. \\ ${ }^{4}$ Department of Molecular Medicine, Faculty of Medicine, University of Malaya, 50603, Kuala Lumpur, Malaysia. \\ ${ }^{5}$ Department of Medical Microbiology, Faculty of Medicine, University of Malaya, 50603 Kuala Lumpur, Malaysia. \\ ${ }^{6}$ Department of Biomedical Sciences, Faculty of Medicine and Health Sciences, University Putra Malaysia, 43400 \\ Selangor, Malaysia.
}

Accepted 19 April, 2013

\begin{abstract}
Candida species are the major cause of mortality in both immunocompromised and critically ill patients. Therefore, the early diagnosis and differentiation of Candida species isolated from clinical samples is principally important due to their inherently variable antifungal resistance pattern. Herein, rapid and species-specific polymerase chain reaction (PCR)-based molecular method was developed for the identification of the four species of Candida most commonly isolated from clinical specimens, namely Candida albicans, Candida parapsilosis, Candida glabrata and Candida tropicalis. The developed method targeted the phospholipase B gene $(P L B)$ as a novel target. We determined the sequences of this gene in previous work. The primers designed achieved highly specific identification of the selected species using simplex PCR assay, which were confirmed by sequencing. There was no cross-amplification of other Candida species nor other fungal organisms tested. The simplex PCR assay yielded detection limits of 1 to $10 \mathrm{cells} / \mathrm{ml}$ and $10 \mathrm{fg} / \mu \mathrm{l}$ DNA. These results showed that the PLB gene provides a novel target that could be used for the identification and detection of medically important Candida species from the clinical samples.
\end{abstract}

Key words: Candida species, identification, polymerase chain reaction (PCR), phospholipase B (PLB) gene.

\section{INTRODUCTION}

Invasive infections by Candida species are the most common cause of mortality in patients undergoing invasive procedures and immunocompromised patients (Ascioglu et al., 2002; Leroy et al., 2009). Therefore, the early diagnosis and differentiation of Candida species isolated from clinical samples is principally important due to their inherently variable antifungal resistance profile (Pfaller et al., 2010). Candida albicans remains the species most commonly isolated and together with Candida tropicalis, Candida glabrata and Candida parapsilosis comprises the most medically important Candida species (Enoch et al., 2006). Therefore, rapid 
Table 1. List of Candida ATCC fungal ATCC strains used in this study.

\begin{tabular}{ll}
\hline Species & Strain $^{*}$ \\
\hline Candida albicans & ATCC 14053 \\
Candida dubliniensis & ATCC MYA-178 \\
Candida famata & ATCC 62894 \\
Candida glabrata & ATCC 2001 \\
Candida guilliermondii & ATCC 6260 \\
Candida kefyr & ATCC 66028 \\
Candida krusei & ATCC 6258 \\
Candida lusitaniae & ATCC 66035 \\
Candida metapsilosis & ATCC 96144 \\
Candida parapsilosis & ATCC 22019 \\
Candida rugosa & ATCC 10571 \\
Candida orthopsilosis & ATCC 96139 \\
Candida tropicalis & ATCC 750 \\
Aspergillus flavus & ATCC 10124 \\
Aspergillus fumigatus & ATCC 36607 \\
Aspergillus niger & ATCC 16888 \\
Aspergillus terreus & ATCC 1012 \\
Cryptococcus neoformans & Clinical Strain 001 \\
Cryptococcus humicolus & Clinical Strain 002 \\
\hline
\end{tabular}

*ATCC, American Type Culture Collection, Rockville, MD, USA.

detection and differentiation of these pathogenic Candida species will assist optimal antifungal treatment and the patient management. Conventional diagnostic methods for the detection and differentiation of pathogenic fungal species are mostly based on the phenotype analysis of fungal cultures. However, these methods are timeconsuming and fail to discriminate between the pathogenic fungal species, information that is essential for initiating specific antifungal therapy (Rickerts et al., 2007). A variety of molecular methods targeting several genes have been developed for identification of medically important Candida species (Schabereiter-Gurtner et al., 2007; Wellinghausen et al., 2009). A number of detection methods are used for identification of the polymerase chain reaction (PCR) products currently used in the clinical microbiology laboratories (Boyanton et al., 2008). However, most methods are either expensive or laborious and clinically not applicable particularly in poor hospital laboratories which have budget limitations (Putignani et al., 2008). Development of simple, rapid and inexpensive molecular approaches that are sensibly applicable to the diagnostic microbiology laboratories are in dire need. Invasion of the outer cell envelope of the host cells by Candida species involves penetration and damage of the cell envelope. Evidence of the role of phospholipases in penetration, injury and lysis of host cell has been proven for $C$. albicans. The gene encoding $C$. albicans phospholipase B1 (PLB1) has been cloned (Hoover et al., 1998). In a prior study, we cloned and sequenced the PLB gene for several Candida species (Cheang et al., 2006). In contrast to the rRNA genes, the PLB gene of most Candida species showed surprisingly large sequence variation. The nucleotide sequence variability between $C$. tropicalis and $C$. glabrata was as much as $75 \%$. To the best of our knowledge, this is the first study to target the PLB gene for the diagnosis of fungal pathogens. The aim of this study is to develop assays specific for the fungal PLB gene, including the development of species-specific PCR method allowing the simultaneous identification and differentiation of medically important Candida species that are most frequently encountered clinically.

\section{MATERIALS AND METHODS}

\section{Source of fungal species}

American type culture collection (ATCC) reference strains of Candida species $(n=13)$, and Aspergillus species $(n=4)$, in addition to two clinical isolates of Cryptococcus species obtained from University Malaya Medical Centre (UMMC) were used in this study to verify the specificity of the designed primers (Table 1).

\section{Culture of fungal species}

The fungal strains were streaked in the Sabouraud dextrose agar (SDA) plate and incubated at $37^{\circ} \mathrm{C}$ for 24 and $48 \mathrm{~h}$ for Candida species and Cryptococcus species, respectively, and for 5 days for Aspergillus species. A single colony of the fungal organism was transferred from SDA plate and cultured in Sabouraud dextrose broth (SDB) for 24 and $48 \mathrm{~h}$ before proceeding to the DNA extraction.

\section{DNA extraction}

The DNA extraction for the fungal species from culture broth was carried out using Wizard $₫$ DNA Purification Kit (Promega, USA). In brief, $1 \mathrm{ml}$ of SDB containing Candida culture was transferred to Eppendorf tube and spun at $13200 \mathrm{rpm}$ for $3 \mathrm{~min}$ to pellet the cells. The supernatant was removed before the addition of $293 \mu$ of 50 $\mathrm{mM}$ EDTA. Subsequently, $7.5 \mu \mathrm{l}$ of $20 \mathrm{mg} / \mathrm{ml}$ of Proteinase $\mathrm{K}$ was added to the mixture and resuspended with pipette. The mixture was incubated at $37^{\circ} \mathrm{C}$ for an hour to digest the cell wall, followed by centrifugation at $13200 \mathrm{rpm}$ for $3 \mathrm{~min}$. Then, $300 \mu \mathrm{l}$ of Nuclei Lysis Solution was added to the pellet and mixed gently with pipette. The mixture was vortexed vigorously with $100 \mu \mathrm{L}$ of Protein Precipitation Solution for $20 \mathrm{~s}$. Next, the tube was cooled on ice for $5 \mathrm{~min}$, followed by centrifugation at $13200 \mathrm{rpm}$ for $5 \mathrm{~min}$. The DNA was precipitated by adding $300 \mu \mathrm{L}$ of $100 \%$ isopropanol to the supernatant. Washing was carried out by addition of $200 \mu \mathrm{L}$ of $70 \%$ ethanol to the pellet. Thirty to fifty microliters of DNA Rehydration Solution was added and mixed with the pellet, before the addition of $1.5 \mu \mathrm{L}$ of RNAse Solution to degrade the existing RNA. The DNA was rehydrated using DNA Rehydration Solution overnight and stored at $-20^{\circ} \mathrm{C}$ until use. Subsequently, Universal PCR amplification of all samples was performed to ensure the appropriate fungal DNA was obtained.

\section{Universal PCR amplification}

The fungal universal primers: the ITS 1 forward primer $\left(5^{\prime}-\mathrm{TCC}\right.$ 
Table 2. Accession No. of Candida species PLB gene sequences used for primers design in this study.

\begin{tabular}{lllll}
\hline Candida strain & Sequence length & Sequence & Accession No. & Source \\
\hline Candida albicans ATCC & $1818 \mathrm{bp}$ & Complete & XM_708729.1 & Jones et al. (2004) \\
Candida glabrata ATCC & $1980 \mathrm{bp}$ & Complete & AF498581 & Unpublished \\
Candida krusei ATCC & $527 \mathrm{bp}$ & Partial 5'end & AY544762 & Cheang et al. (2006) \\
Candida parapsilosis ATCC & $546 \mathrm{bp}$ & Partial 3'end & AY544774 & Cheang et al. (2006) \\
Candida parapsilosis clinical strain & $546 \mathrm{bp}$ & Partial 3'end & AY544775 & Cheang et al. (2006) \\
Candida tropicalis ATCC & $595 \mathrm{bp}$ & Partial 5'end & AY394565 & Cheang et al. (2006) \\
Candida tropicalis ATCC & $423 \mathrm{bp}$ & Partial 3'end & AY389800 & Cheang et al. (2006) \\
Candida tropicalis clinical strain & $594 \mathrm{bp}$ & Partial 5'end & AY394566 & Cheang et al. (2006) \\
Candida tropicalis clinical strain & $423 \mathrm{bp}$ & Partial 3'end & AY389801 & Cheang et al. (2006) \\
\hline
\end{tabular}

GTA GGT GAA CCT GCG G-3') and ITS4 reverse primer (5'- TCC TCC GCT TAT TGA TAT GC-3') were used, because it flanks common sequences among all fungal species (White et al., 1990). An amount of $0.5 \mu \mathrm{L}$ of extracted DNA was added to the mixture of 1x PCR buffer, $1.5 \mathrm{mM}$ of $\mathrm{MgCl}_{2}, 0.08 \mathrm{mM}$ of dNTPs (Promega, USA), $0.2 \mathrm{pmol} / \mu \mathrm{L}$ of each of the ITS 1 and ITS 4 primers (AITBiotech, Singapore), $0.02 \mathrm{U}$ of Go Taq DNA polymerase (Promega, USA) and sterile ultrapure water to make up a total volume of 25 $\mu \mathrm{L}$. The reaction was started with the initial denaturation at $95^{\circ} \mathrm{C}$ for $5 \mathrm{~min}$, followed by 30 cycles of denaturation, annealing and extension at $95^{\circ} \mathrm{C}$ for $30 \mathrm{~s}, 55^{\circ} \mathrm{C}$ for $30 \mathrm{~s}$, and $72^{\circ} \mathrm{C}$ for $1 \mathrm{~min}$, respectively. The reaction was terminated after final extension at $72^{\circ} \mathrm{C}$ for $10 \mathrm{~min}$. Hot-start PCR was used whereby the DNA polymerase was added to the reaction mixture after 5 min of initial denaturation. Subsequently, the PCR products were analyzed by gel electrophoresis and visualized via the Alphalmager HP imaging system.

\section{Specific primer design}

C. albicans, C. glabrata, C. parapsilosis and C. tropicalis were selected and the nucleotide sequences of their PLB gene were downloaded from the GenBank database (http://www.ncbi.nlm.nih.gov/). Table 2 shows the accession numbers and sources of the sequences used in this study. The PLB gene sequences from different Candida species were aligned and compared to find out the unique region of each species, assisted by ClustalW sequence alignment software. The species-specific primers for PCR assay were designed based on the most unique sequences that can be found between the Candida species from the PLB gene. The sequences of the designed primers were compared with the GenBank database using blastn (http://blast.ncbi.nlm.nih.gov/Blast.cgi) to ensure their specificities for the corresponding Candida species before being chemically synthesized. All primers were synthesized by AIT-Biotech (Singapore).

\section{PCR amplification using species-specific primers}

An amount of $0.5 \mu \mathrm{g}$ of extracted DNA was added to the mixture of $1 \times$ PCR buffer, $1.5 \mathrm{mM}$ of $\mathrm{MgCl}_{2}, 0.08 \mathrm{mM}$ of dNTPs (Promega, USA), $0.4 \mathrm{pmol} / \mu \mathrm{l}$ of species-specific forward and reverse primers (AIT-Biotech, Singapore), respectively, $0.02 \mathrm{U}$ of Go Taq DNA polymerase (Promega, USA) and sterile ultrapure water to make up a total volume of $25 \mu \mathrm{l}$. The reaction was started with the initial denaturation at $95^{\circ} \mathrm{C}$ for $5 \mathrm{~min}$ and followed by 30 cycles of denaturation, annealing and extension at $95^{\circ} \mathrm{C}$ for $30 \mathrm{~s}, \mathrm{X}^{\circ} \mathrm{C}\left(\mathrm{X}^{\circ} \mathrm{C}=\right.$ the optimal annealing temperature for each primer set) for $35 \mathrm{~s}$ and $72^{\circ} \mathrm{C}$ for $1 \mathrm{~min}$, respectively. The reaction was terminated after final extension at $72^{\circ} \mathrm{C}$ for $10 \mathrm{~min}$. Hot-start PCR was used whereby the DNA polymerase was added to the reaction mixture after 5 min of initial denaturation. The PCR products were visualized under UV light after gel electrophoresis and compared with the expected band size of the corresponding Candida species. The PCR products were then purified using QIAquick PCR Purification Kit (Qiagen, USA). Eventually, the purified PCR products were sent to a commercial company (First BASE, Malaysia) and subjected to automated sequencing on both strands using the specific forward and reverse primers for correspondent species of the speciesspecific PCR.

\section{Specificity test of the species-specific PCR}

For the specificity test of the developed PCR, a number of PCRs were run using DNA template from the extracted DNA of the ATCC reference strains of Candida species $(n=13)$, Aspergillus species $(n=4)$ and also two clinical isolates of Cryptococcus species to verify the ability of the designed primers to only amplify the DNA segment of the correspondent Candida species.

\section{Sensitivity test}

The concentration of Candida grown in SDB was determined using haemocytometer. Six different concentrations of Candida culture were prepared from $10^{5}, 10^{4}, 10^{3}, 10^{2}, 10^{1}$ to $1 \mathrm{cell} / \mathrm{ml}$. The DNA was extracted using Wizard @ DNA Purification Kit (Promega, USA) from each concentration. The extracted DNA was used as template in the PCR assay using species-specific primers. On the other hand, extracted DNA from each Candida species was purified using the DNeasy Blood and Tissue Kit (Qiagen, USA) and the concentration was measured using the Nanophotometer (Implen, Germany), and 9 different concentrations of each Candidal DNA: $100 \mathrm{ng}, 10 \mathrm{ng}, 1 \mathrm{ng}, 0.1 \mathrm{ng}, 10 \mathrm{pg}, 1 \mathrm{pg}, 0.1 \mathrm{pg}, 10 \mathrm{fg}$ and $1 \mathrm{fg} / \mu \mathrm{l}$ were prepared and used as template in PCR using the speciesspecific primers.

\section{RESULTS}

\section{PCR amplification using ITS1 and ITS4 primers}

Due to the difference in length between both ITS1 and ITS2 regions of different Candida species, amplicons 
A
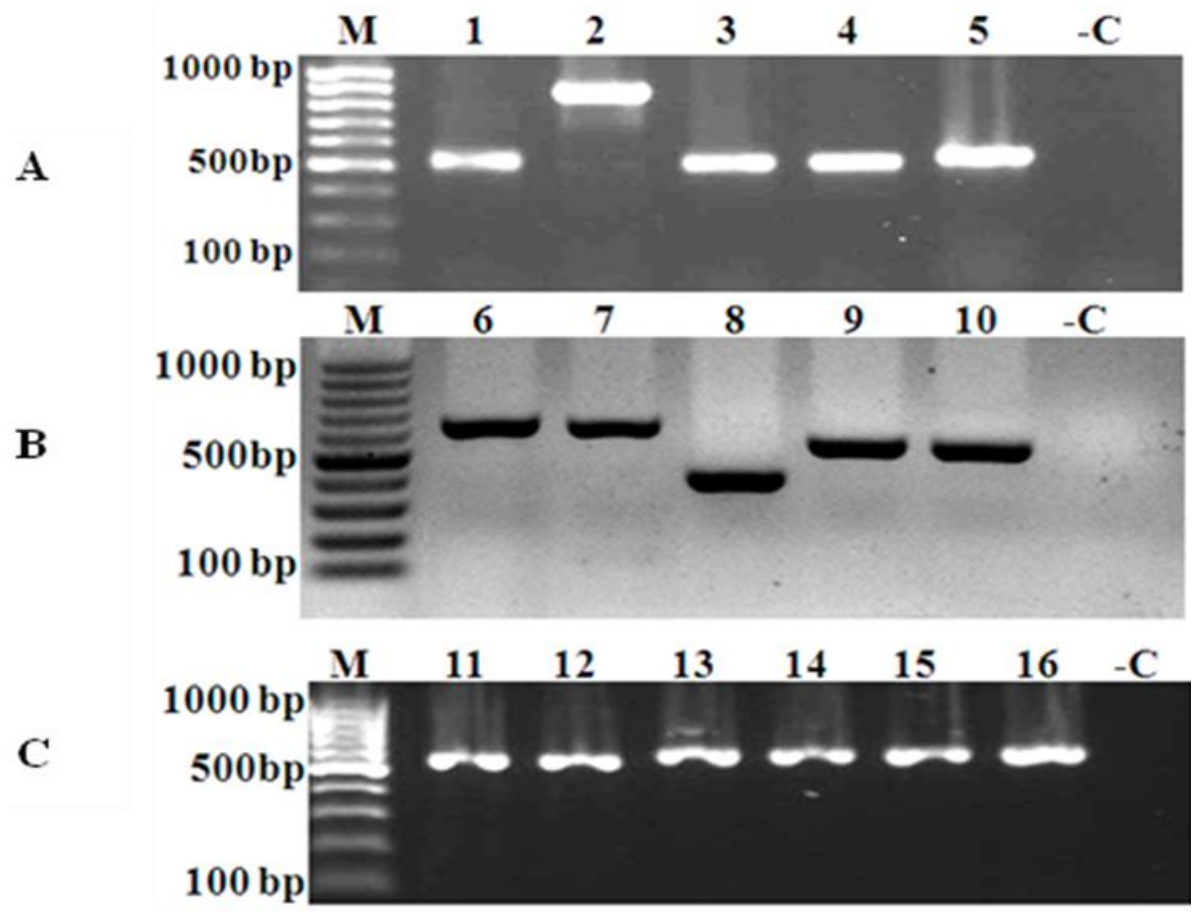

Figure 1. Representative gel electrophoresis of the ITS1 and ITS4 PCR products. Lanes 1 to 16: C. albicans ATCC ( 530 bp), C. glabrata ATCC ( $870 \mathrm{bp})$, C. parapsilosis ATCC $(\sim 515 \mathrm{bp})$, C. tropicalis ATCC ( 520bp), C. albicans ATCC ( 530 bp), C.famata ATCC ( 625 bp), C. guilliermondii ATCC ( 610 bp), C. lusitaniae ATCC ( 370bp), C. metapsilosis ATCC ( 517 bp), C. orthopsilosis ATCC ( 513 bp), Cryptococcus neoformans 001 ( 555 bp), Cryptococcus humicolus 002 ( 550bp), Aspergillus fumigatus, Aspergillus flavus, Aspergillus niger, Aspergillus terreus (600-610 bp), respectively, Lane C: negative control which contains sterile distilled water instead of DNA template, lane M: DNA molecular marker (Fermentas).

which are different in size can be produced during the PCR. According to Figure 1, the PCR products of $C$. albicans, C. glabrata, C. parapsilosis and C. tropicalis ATCC strains, using ITS1 and ITS4 primers were approximately $530,870,515$ and $520 \mathrm{bp}$, respectively (Figure 1A). The ITS1 and ITS4 PCR amplification results of other ATCC strains of Candida species such as Candida famata, Candida guilliermondii, Candida Iusitaniae, Candida metapsilosis and Candida orthopsilosis are also shown in Figure 1B with product sizes of approximately 625, 610, 370, 517 and $513 \mathrm{bp}$, respectively. In addition, the ITS1 and ITS4 PCR products of Cryptococcus neoformans 001 (clinical isolate), Cryptococcus humicolus 002 (clinical isolate), Aspergillus fumigatus, Aspergillus flavus, Aspergillus niger and Aspergillus terreus ATCC and the product size were approximately 555,550 bp for Cryptococcus species and 600 to 610 bp for Aspergillus species, respectively (Figure $1 \mathrm{C}$ ).

\section{Primers design}

Species-specific PCR assay was developed to selectively identify and differentiate between the four most common Candida species isolated from clinical specimens namely, C. albicans, C. glabrata, C. parapsilosis and C. tropicalis. The developed PCR method targeted the PLB gene as a novel target and to specifically amplify segments from the PLB gene of the selected Candida species, specific primers were designed. Indeed, with the assistance of ClustalW sequence alignment software, the PLB gene sequences from Candida species tested were aligned and compared to find out the unique region of each species. Four species-specific primer pairs were designed successfully based on the most unique sequences that can be found between the Candida species from the PLB gene.

Table 3 shows the sequences, lengths and the annealing temperatures of the designed primers, in addition to the product lengths.

\section{Specificity test of the species-specific PCR primers}

The Candida species-specific primers of the developed PCR were tested in terms of specificity using fungal ATCC strains. Thirteen Candida species (ATCC strains), 
Table 3. The sequences, lengths and product lengths of the PCR primers.

\begin{tabular}{|c|c|c|c|c|}
\hline Candida species & Primer ID & Sequence $5^{\prime}--3^{\prime}$ & $\begin{array}{l}\text { Annealing } \\
\text { temperature }\end{array}$ & $\begin{array}{l}\text { Product } \\
\text { length }\end{array}$ \\
\hline \multirow{2}{*}{ C. albicans } & CAF & TTGTGTTGCTACATCACCAAC & \multirow{2}{*}{$63^{\circ} \mathrm{C}$} & \multirow{2}{*}{$538 \mathrm{bp}$} \\
\hline & CAR & TTTGCTGGCAACTTGATTACC & & \\
\hline \multirow{2}{*}{ C. glabrata } & $\mathrm{CgF}$ & TCTCACACTССАТTGTCTCA & \multirow{2}{*}{$50^{\circ} \mathrm{C}$} & \multirow{2}{*}{$404 \mathrm{bp}$} \\
\hline & $\mathrm{CgR}$ & AGCAGGTTTACCATCAGAA & & \\
\hline \multirow{2}{*}{ C. parapsilosis } & CPF & TCCATCGACGAATTGATTG & \multirow{2}{*}{$60^{\circ} \mathrm{C}$} & \multirow{2}{*}{252 bp } \\
\hline & CPR & ACCGTTTTGAGACCTCAAG & & \\
\hline \multirow{2}{*}{ C. tropicalis } & CTF & CCCATACGATTTATGGAAT & \multirow{2}{*}{$53^{\circ} \mathrm{C}$} & \multirow{2}{*}{$501 \mathrm{bp}$} \\
\hline & CTR & CCATTGACACAAGCATTTAC & & \\
\hline
\end{tabular}

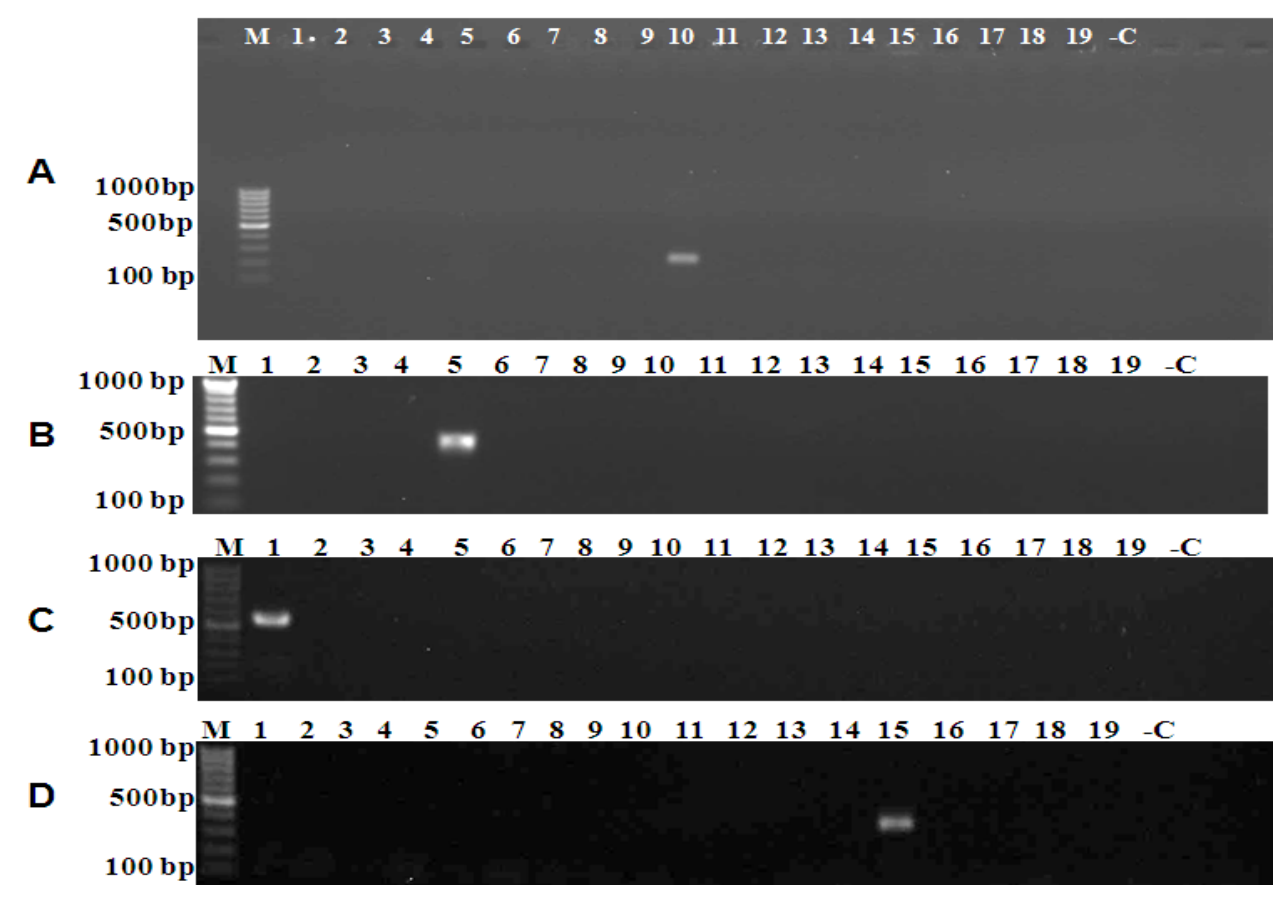

Figure 2. Representative gel electrophoresis of the specificity test of the species-specific PCR using Candida species-specific primers with DNA of $C$. albicans and other ATCC reference strains (A, B, C and D: using C. parapsilosis, C. glabrata, C. albicans and C. tropicalis specific primers, respectively). Lanes 1: C. albicans, 2: $C$. dubliniensis, 3 C. famata, 4: $C$. guilliermondii, 5: C. glabrata , 6: C. kefyr, lane 7: C. krusei, 8:C. lusitaniae, 9: C. metapsilosis, 10: C. parapsilosis, 11: C. orthopsilosis, 12: C. rugosa, 13: Cryptococcus neoformans, 14: C. humicolus, 15: $C$. tropicalis, 16 Aspergillus fumigatus, 17: A. niger, 18: A. terreus, 19: $A$. flavus, lane C: negative control which contains sterile distilled water instead of DNA template, lane M: DNA molecular marker.

4 Aspergillus species (ATCC strains) and 2 Cryptococcus species (clinical isolates) were cultured and their DNA were extracted and used as a template to amplify the species-specific PCR. Figure 2A, B, C and D showed that, the species-specific primers were able to anneal to their specific targeted sites during PCR. The annealing of these primers to the targeted DNA had allowed the amplification of the targeted sequences subsequently generated PCR products, which are about 252, 404, 538 and 501 bp in length for $C$. parapsilosis, C. glabrata, C. albicans and C. tropicalis, respectively, and were subsequently confirmed by sequencing of the PCR products. There was no non-specific priming of DNA from other Candida species or fungal species being observed.

\section{Sensitivity test of the species-specific PCR}

The sensitivity of the species-specific PCR identification and amplification method was determined using different 


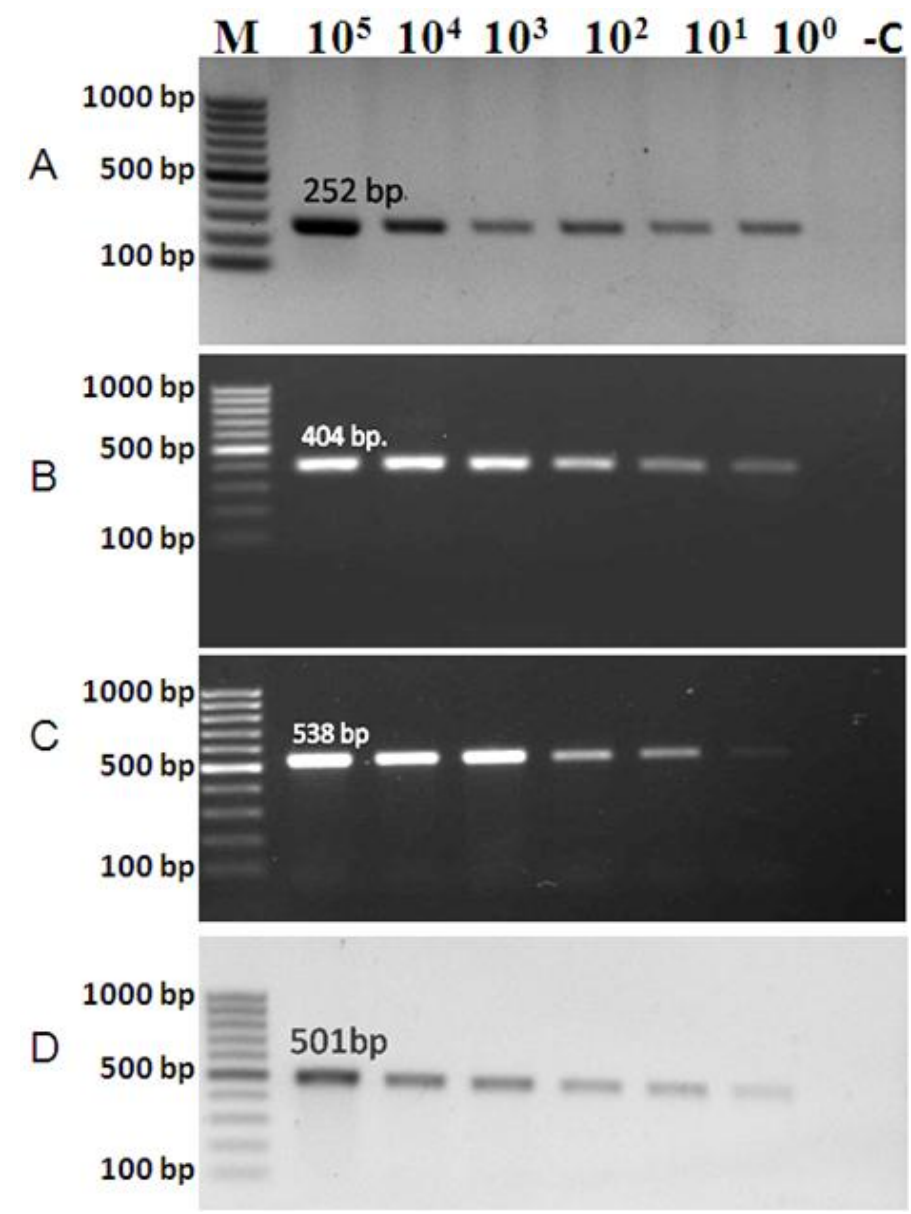

Figure 3. Representative gel electrophoresis of the sensitivity test of the species-specific PCR using cell dilutions methods $(A, B, C$ and D: using $C$. parapsilosis, C. glabrata, $C$. albicans and $C$. tropicalis specific primers and DNA, respectively). Lanes 1 to 6: cell concentration $10^{5}, 10^{4}, 10^{3}, 10^{2}, 10^{1}$ and $1 \mathrm{cell} / \mathrm{mL}$, respectively. Lane C: negative control which contains sterile distilled water instead of DNA template, lane M: DNA molecular marker.

concentrations of Candida species DNA, from dilutions of both cells and purified DNA. The sensitivity of the cell PCR amplification method was determined using six different concentrations of Candida species DNA, from $10^{5}$ to 1 cells $/ \mathrm{mL}$ which were used together with the Candida species specific primers during the speciesspecific PCR. Figure $3 A, B, C$ and $D$ shows that the intensity of the bands was decreased starting from $10^{2}$ to 1 cells/mL gradually. The detection limits of this method were from 1 to 10 cells $/ \mathrm{mL}$.

In addition to the cell dilution method, the sensitivity of the species-specific PCR detection and amplification method was determined using nine different concentrations of purified Candida species DNA from 100 $\mathrm{ng} / \mu \mathrm{l}$ to $1 \mathrm{fg} / \mu \mathrm{l}$, which were prepared and used together with the Candida species-specific primers during the species-specific PCR. Figure 4A, B, C and D showed that, an expected band of each of the targeted Candida species was observed on the ethidium-bromide-stained Agarose gel under UV light. The intensity of the bands was decreased starting from $100 \mathrm{ng} / \mu \mathrm{l}$ to $1 \mathrm{fg} / \mu \mathrm{l}$ gradually, and the detection limit range of this method was from 10 to $1 \mathrm{fg} / \mu$ l.

\section{DISCUSSION}

Detection and identification of fungal DNA by PCR is one of the most powerful and popular tools for the early detection and identification of pathogenic fungi, including Candida species (White et al., 2009). The speciesspecific PCR method described in the current study has offered all the needed characteristics: it is simple to conduct, rapid in identification of Candida species, sensitive in detection, and the results are highly reproducible. For the PCR parameters and conditions for all the species-specific primers, identification of Candida species are similar except the annealing temperature. Due to utilization of the same concentration of volume for all the PCR reagents, including the species-specific primers, it has simplified and reduced the confusion of the individual who handles the experiments. The "presence or absence" of the band identification system has eased process of analyzing the result by only observing the ethidium bromide stained agarose gel under the exposure of UV light.

The total time required for identification of Candida species using species-specific PCR is less than $5 \mathrm{~h}$ including $2 \mathrm{~h}$ for DNA extraction, $1 \mathrm{~h}$ and $40 \mathrm{~min}$ for PCR and $40 \mathrm{~min}$ agarose gel electrophoresis. It is considered rapid as the identification can be done within a working day, as compared to conventional biochemical tests which require more than 5 days, and other molecular methods using RFLP (Mirhendi et al., 2006, 2010) and ELISA detection (Badiee et al., 2009), which require 2 days and more than $7 \mathrm{~h}$, respectively, for the identification of Candida species.

The PLB gene of Candida species is chosen as the site of designing Candida species-specific primers as a novel target which shows high variability of sequences among Candida species. Thus, this provided several unique sequences for each Candida species which enabled the designing of species-specific primers that targeted the unique sequences of the PLB gene. In contrast, the most commonly targeted genes (rRNA genes), contain largely conserved regions which are common for all fungal organisms and limited variable areas known as the internal transcribed spacer (ITS) regions (Yeo and Wong, 2002; Graf et al., 2004). Previously, the most reliable method for identification and differentiation between Candida species is based on the sequencing of the ITS or D1/D2 regions of the rRNA gene (Desnos-Ollivier et al., 2008). Although DNA sequencing is a highly specific tool, it adds additional cost to the identification of Candida species, and delays the results which are not desirable in 


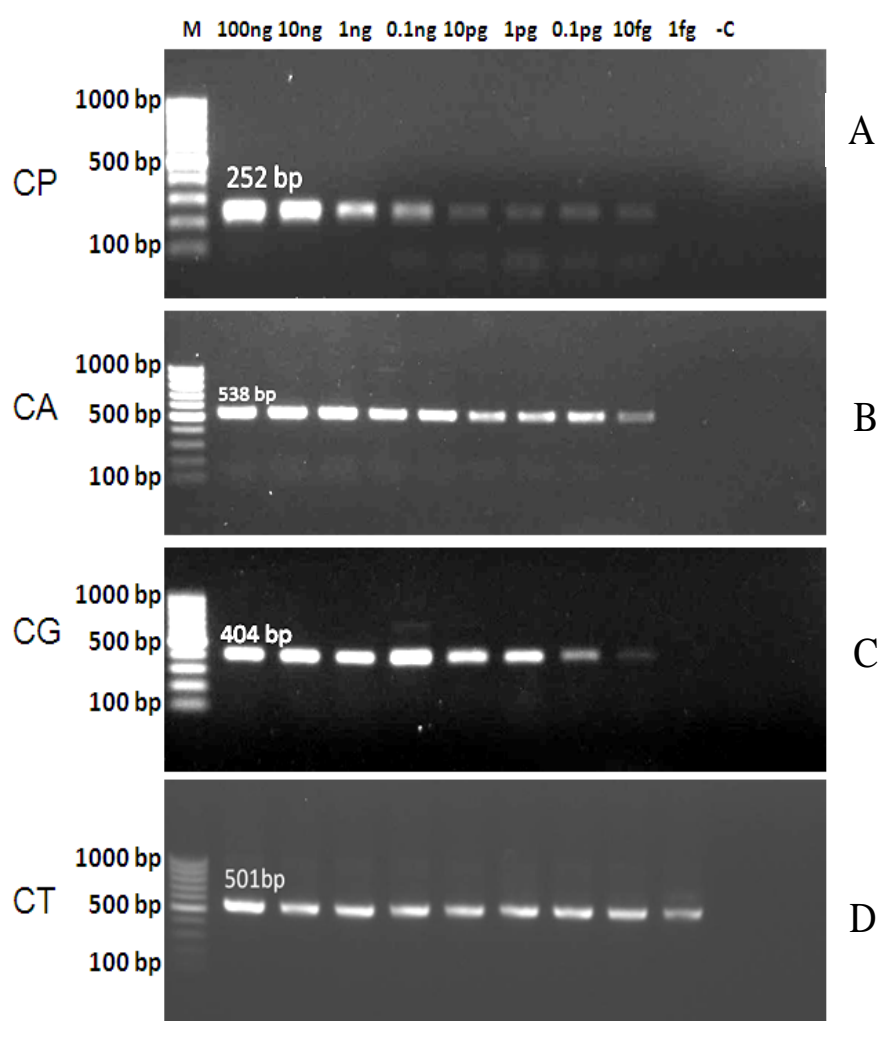

Figure 4. Representative gel electrophoresis of the sensitivity test of the species-specific PCR using serial dilutions of purified DNA (100 ng/ $/ \mathrm{l}$ to $1 \mathrm{fg} / \mu \mathrm{l})$ of the different Candida species (A, B, C and D: using C. parapsilosis, C. glabrata, C. albicans and $C$. tropicalis specific primers and DNA, respectively). Lane C: negative control which contains sterile distilled water instead of DNA template, lane M: DNA molecular marker.

clinical laboratories. In the current study, species-specific primers for 4 selected Candida species were designed. C. albicans, C. glabrata, C. parapsilosis and C. tropicalis were the species selected because these are considered the most commonly isolated Candida species from clinical specimens, and accounted for $94.6 \%$ of clinical isolates from bloodstream infection (Pfaller, et al., 2010). The high variability in the PLB gene among Candida species allowed the designing of species-specific primers that produce distinctive product size for each of the 4 Candida species studied. Consequently, these had allowed the specific identification of Candida species directly from the gel picture without the need for DNA sequencing, which is easier, faster and less costly.

In order to confirm the specificity of the Candida species-specific primers, the experiments were repeated at least three times using the extracted Candida DNA and other fungal DNA to confirm the reproducibility of the results. The species-specific primers were found to be specific to their targeted Candida DNA with no crosspriming to DNA from other Candida species or other fungal species in all the experiments using ATCC strains.
In a previous study conducted by Fujita et al. (2001), the authors targeted the ribosomal RNA genes in PCR which is followed by either agarose gel electrophoresis or microchip electrophoresis to test a total of 120 fungal strains. Nonetheless, in that study, $C$. albicans and $C$. dubliniensis could not be differentiated because of their nearly identical amplicon sizes. The major limitation of that method is the inability to detect the mixed fungal infections of more than one pathogenic strain due to the overlapping of the products size ranges of some Candida species. Furthermore, the presence of mixed normal flora in the clinical specimens made the fungal identification difficult. In contrast, the present study clearly discriminates between the targeted 4 major Candida species with at least $100 \mathrm{bp}$ differences among the PCR products between each two different Candida species by the developed method. The reason behind that is related to the high variation in the PLB gene sequences among Candida species which enable designing of well quality species-specific primers.

More recently, a multiplex tandem PCR (MT-PCR) assays targeting internal transcribed spacer region, $\beta$ tubulin genes and elongation factor $1-\alpha$ were developed and evaluated for direct detection and identification of fungal pathogens from positive blood culture samples (Lau et al., 2008, 2010). The MT-PCR platform utilized in the previous studies have an advantage over other realtime multiplexing platforms like microarrays and Luminex technology, in that it utilizes Evagreen dye and melting curve analysis for identification of fungal species and does not require specialized and expensive equipment like flow cytometer. However, the applications of real-time PCR based methods in clinical microbiology laboratories are exclusively for serious viral infections and difficult or non-cultivable bacterial pathogens. In addition, it is considered expensive when compared with the conventional diagnostic methods. Thus, the development of inexpensive DNA-based molecular techniques like the species-specific PCR of the current study may enhance the applications of the molecular methods as routine diagnostic tools in the clinical microbiology laboratories for identification and detection of pathogenic Candida species. The detection limit for PCR using cultureextracted DNA in this study is 1 to $10 \mathrm{cells} / \mathrm{ml}$. The excellent sensitivity of this identification method results not only from the choice of the novel PCR amplification target, which is the PLB gene but also from the optimization of the DNA preparation method and PCR conditions as well. Indeed, the newly developed PCR method using species-specific primers targeting the PLB gene for differentiation of Candida species in this study has provided desirable results, in terms of specificity and sensitivity. In addition, the developed method is easy to conduct and generate diagnostic results within one working day. Moreover, the advantages of the speciesspecific PCR in its flexibility of adding more newly developed species-specific primers covering other 
medically important human pathogens make it a useful molecular tool for rapid identification of a wide range of pathogenic organisms at species level.

\section{REFERENCES}

Ascioglu S, Rex J, De Pauw B, Bennett J, Bille J, Crokaert F, Denning D, Donnelly J, Edwards J, Erjavec Z (2002). Defining opportunistic invasive fungal infections in immunocompromised patients with cancer and hematopoietic stem cell transplants: An international consensus. Clin. Infect. Dis. 34:7-14.

Badiee P, Kordbacheh P, Alborzi A, Zakernia M, Haddadi P (2009). Early detection of systemic candidiasis in the whole blood of patients with hematologic malignancies. Jpn. J. Infect. Dis. 62:1-5.

Boyanton JBL, Luna RA, Fasciano LR, Menne KG, Versalovic J (2008). DNA pyrosequencing-based identification of pathogenic Candida species by using the internal transcribed spacer 2 region. Arch. Pathol. Lab. Med. 132:667-674.

Cheang P, Chong P, Shamsudin M, Ng K (2006). Cloning of Phospholipase B Gene Homology in Candida species via Degenerate PCR. Biomed. Res. 17:117-123.

Desnos-Ollivier M, Ragon M, Robert V, Raoux D, Gantier J, Dromer F (2008). Debaryomyces hansenii (Candida famata), a rare human fungal pathogen often misidentified as Pichia guilliermondii (Candida guilliermondii). J. Clin. Microbiol. 46:3237-3242.

Enoch DA, Ludlam HA, Brown NM (2006). Invasive fungal infections: A review of epidemiology and management options. J. Med. Microbiol. 55:809-818

Fujita SI, Senda Y, Nakaguchi S, Hashimoto T (2001). Multiplex PCR using internal transcribed spacer 1 and 2 regions for rapid detection and identification of yeast strains. J. Clin. Microbiol. 39:3617-3622.

Graf B, Trost A, Eucker J, Göbel U, Adam T (2004). Rapid and simple differentiation of $C$. dubliniensis from $C$. albicans. Diagn. Microbiol. Infect. Dis. 48:149-151.

Hoover Cl, Jantapour MJ, Newport G, Agabian N, Fisher SJ (1998). Cloning and regulated expression of the Candida albicans phospholipase B (PLB1) gene. FEMS. Microbiol. Lett. 167:163-169.

Jones T, Federspiel NA, Chibana H, Dungan J, Kalman S, Magee BB, Newport G, Thorstenson YR, Agabian N, Magee PT (2004). The diploid genome sequence of Candida albicans. Proc. Natl. Acad. Sci. U. S. A. 101:7329-7334.

Lau A, Halliday C, Chen SCA, Playford EG, Stanley K, Sorrell TC (2010). Comparison of whole blood, serum, and plasma for early detection of candidemia by Multiplex-Tandem PCR. J. Clin. Microbiol. 48:811-816.

Lau A, Sorrell T, Chen S, Stanley K, Iredell J, Halliday C (2008). Multiplex-tandem PCR: A novel platform for the rapid detection and identification of fungal pathogens from blood culture specimens. J. Clin. Microbiol. 46(9):3021-3027.
Leroy O, Gangneux JP, Montravers P, Mira JP, Gouin F, Sollet JP, Carlet J, Reynes J, Rosenheim M, Regnier B (2009). Epidemiology, management, and risk factors for death of invasive Candida infections in critical care: A multicenter, prospective, observational study in France (2005-2006). Crit. Care Med. 37:1612-1618.

Mirhendi H, Bruun B, Schonheyder HC, Christensen JJ, Fuursted K, Gahrn-Hansen B, Johansen HK, Nielsen L, Knudsen JD, Arendrup MC (2010). Molecular screening for Candida orthopsilosis and Candida metapsilosis among Danish Candida parapsilosis group blood culture isolates: Proposal of a new RFLP profile for differentiation. J. Med. Microbiol. 59:414-420.

Mirhendi H, Makimura K, Khoramizadeh M, Yamaguchi H (2006). A one-enzyme PCR-RFLP assay for identification of six medically important Candida species. Jpn. J. Med. Mycol. 47:225-229.

Pfaller M, Castanheira M, Messer S, Moet G, Jones R (2010). Variation in Candida spp. distribution and antifungal resistance rates among bloodstream infection isolates by patient age: Report from the SENTRY Antimicrobial Surveillance Program (2008-2009). Diagn. Microbiol. Infect. Dis. 3:278-283.

Putignani L, Paglia MG, Bordi E, Nebuloso E, Pucillo LP, Visca P (2008). Identification of clinically relevant yeast species by DNA sequence analysis of the D2 variable region of the 25-28S rRNA gene. Mycoses. 51:209-227.

Rickerts V, Mousset S, Lambrecht E, Tintelnot K, Schwerdtfeger R, Presterl E, Jacobi V, Just-Nübling G, Bialek R (2007). Comparison of histopathological analysis, culture, and polymerase chain reaction assays to detect invasive mold infections from biopsy specimens. Clin. Infect. Dis. 44:1078-1083.

Schabereiter-Gurtner C, Selitsch B, Rotter ML, Hirschl AM, Willinger B (2007). Development of novel real-time PCR assays for detection and differentiation of eleven medically important Aspergillus and Candida species in clinical specimens. J. Clin. Microbiol. 45:906-914.

Wellinghausen N, Siegel D, Winter J and Gebert S (2009). Rapid diagnosis of candidaemia by real-time PCR detection of Candida DNA in blood samples. J. Med. Microbiol. 58:1106-1111.

White PL, Perry MD and Barnes RA (2009). An update on the molecular diagnosis of invasive fungal disease. FEMS. Microbiol. Lett. 296:110.

White TJ, Bruns T, Lee S and Taylor J (1990). Amplification and direct sequencing of fungal ribosomal RNA genes for phylogenetics. PCR. Protoc. 315-322.

Yeo S, Wong B (2002). Current status of nonculture methods for diagnosis of invasive fungal infections. Clin. Microbiol. Rev. 15:465484 . 